\title{
Modification of Plant Height via RNAi Suppression of MdGA20-ox Gene Expression in Apple
}

\author{
Kai Zhao \\ College of Horticulture, Shenyang Agricultural University, 120 Dongling Road, 110866 Shenyang, \\ Liaoning, China; and Department of Agricultural Engineering, Songyuan Vocational Technical \\ College, 820 Zhongshan Street, 138005 Songyuan, Jilin, China \\ Feng Zhang \\ College of Bioscience and Biotechnology, Shenyang Agricultural University, 120 Dongling Road, \\ 110866 Shenyang, Liaoning, China \\ Yi Yang, Yue Ma, Yuexue Liu, He Li, Hongyan Dai, and Zhihong Zhang ${ }^{1}$ \\ College of Horticulture, Shenyang Agricultural University, 120 Dongling Road, 110866 Shenyang, \\ Liaoning, China
}

\begin{abstract}
Additional INDEX wORDs. gene silencing, dwarf, Malus
Abstract. GA20-oxidase (GA20-ox) is a key enzyme involved in the biosynthesis of gibberellic acid (GA). To investigate its role in plant growth and development, we suppressed MdGA20-ox gene expression in apple (Malus domestica cv. Hanfu) plants by RNA interference (RNAi). After 20 weeks of growth in the greenhouse, significant phenotype differences were observed between transgenic lines and the nontransgenic control. Suppression of MdGA20-ox gene expression resulted in lower plant height, shorter internode length, and higher number of nodes compared with the nontransgenic control. The expression of MdGA20-ox in transgenic plants was significantly suppressed, and the active GA content in transgenic lines was lower than that in the nontransgenic control. These results demonstrated that the $M d G A 20-o x$ gene plays an important role in vegetative growth, and therefore it is possible to develop dwarfed or compact scion apple cultivars by MdGA20-ox gene silencing.
\end{abstract}

Apple is one of the most widely cultivated fruit crops in the world. Tree size is critical for early, high yielding, and efficient apple crops. Dwarf trees require reduced spray volumes, produce higher yields per unit of land through higher planting densities (Atkinson and Else, 2001), and allow mechanical harvesting. Development of compact apples through conventional breeding may control growth (Talwara et al., 2013), but it is a costly and time-consuming approach with a high probability of adverse changes in fruit characteristics. Chemical growth retardants are used as a supplementary treatment to control excessive vegetative growth, but decrease profitability (Wiesman and Lavee, 1994). Apple trees become smaller in size when scions are grafted on dwarfing rootstocks or interstocks. Dwarfing rootstocks impart characteristics to the tree as early flowering from planting, more efficient stable yield, and reduced vegetative growth.

Most growth retardants act by inhibiting the biosynthesis of GA, a class of plant hormones. GA plays important roles in plant development, including stem growth, leaf expansion, flower development, fruit set, and seed germination (Yamaguchi, 2008). Studies have revealed that one of the most obvious functions of GA is to promote vegetative growth, including the elongation of stems and the expansion of leaves (Olszewski et al., 2002). GA-deficient mutants tend to have small and dark green leaves and reduced stem length (Wang et al., 2012a). Application

Received for publication 15 Apr. 2015. Accepted for publication 22 Feb. 2016. This work was supported by the National Natural Science Foundation of China (grant no. 31171927) and the Agricultural Science and Technology Research Projects of Liaoning Province (no. 2014204004).

${ }^{1}$ Corresponding author. E-mail: zhang_sau@163.com. of exogenous active GA on wild plants or increased GA levels in mutants results in tall and spindly phenotypes (Fagoaga et al., 2007). Most of GA-deficient mutants have a dwarf phenotype with significantly decreased GA content and can be restored to normal phenotype by spraying with $\mathrm{GA}_{3}$ solution (Wang et al., 2012b). The GA biosynthetic pathway has been well characterized and can be divided into three major stages according to the localization and the enzymes involved (Lee and Zeevaart, 2007). The final stages of GA biosynthesis require the action of 2-oxoglutarate-dependent dioxygenases, including the GA20-ox that catalyzes the penultimate step in the formation of bioactive GA, and has been shown to be an important regulator in GA biosynthesis pathway (Zhao et al., 2010).

The aim of this study was to develop dwarf apple lines by silencing of the MdGA20-ox gene.

\section{Materials and Methods}

Plant material and growing conditions. In this study, Hanfu, an elite apple cultivar developed by Shenyang Agricultural University (Shenyang, China), was used for plant transformation and isolation of GA20-ox genes. Cultures were maintained at $23^{\circ} \mathrm{C}$ day $/ 18^{\circ} \mathrm{C}$ night under a 16 -h photoperiod. In vitro plants of Malus hupehensis 'Pingyitiancha' were maintained under field conditions and used for the isolation of GA20-ox genes.

NuCleic ACID EXTRACTion. Genomic DNA was isolated from apple shoots as described by Tai and Tanksley (1990). Total RNA was isolated from leaves using the modified cetyltrimethylammonium bromide method (Chang et al., 2007) and treated 
Table 1. Primers' sequence amplified for the fragment of MdGA20-ox gene, sense or antisense of RNAi vector, nptII gene, and MdGA20-ox gene in nontransgenic and the transgenic lines, and semiquantitative and quantitative PCR of 'Hanfu' apple.

\begin{tabular}{|c|c|c|}
\hline Primer $^{z}$ & Sequences of sense and antisense primers $\left(5^{\prime}\right.$ to $\left.3^{\prime}\right)$ & Amplification \\
\hline PF1 & CCTTCCCCAACTCACATACA & \\
\hline PR1 & ТСТCСССТGCTTTCCTTTCA & MdGA20-ox gene fragment \\
\hline PF2 & GCCTCGAGCCTTCCCCAACTCACATACA ${ }^{\mathrm{y}}$ & \\
\hline PF3 & СТАAGCTTTCTCСССТGCTTTCCTTTCA & Antisense fragment of RNAi vector \\
\hline PR3 & GCT्TCAGACCTTCCCCAACTCACATACA & \\
\hline PF4 & GTTCTTTTTGTCAAGACCGACC & \\
\hline PF5 & GGACAGTAGAAAAGGAAGGT & \\
\hline PR5 & GAAAATGTATGTGAGTTGGG & Detecting $M d G A 20$-ox gene \\
\hline $\operatorname{actinF}(S Q)^{x}$ & ATCGTGGTCATTGGCCATGT & \\
\hline $\operatorname{actinR}(\mathrm{SQ})$ & AGCCTGTGAGGTTCCAGTAATCAT & Semiquantitative PCR \\
\hline $\operatorname{actin} F(Q)^{\mathrm{w}}$ & CCTTCGTCTTCGGCTTGTTC & \\
\hline $\operatorname{actin} R(Q)$ & GGAGCATCATCACCAGCAAA & Quantitative PCR \\
\hline
\end{tabular}

${ }^{\mathrm{z} P F}=$ sense primer; $\mathrm{PR}=$ antisense primer.

${ }^{\mathrm{y}}$ Characters with underscore stand for sites of restriction endonuclease.

${ }^{\mathrm{x}} \mathrm{SQ}=$ semiquantitative PCR, expression levels of the MdGA20-ox gene in transgenic lines and the nontransgenic lines.

${ }^{\mathrm{w}} \mathrm{Q}=$ quantitative $\mathrm{PCR}$, expression levels of the MdGA20-ox gene in transgenic lines and the nontransgenic lines.

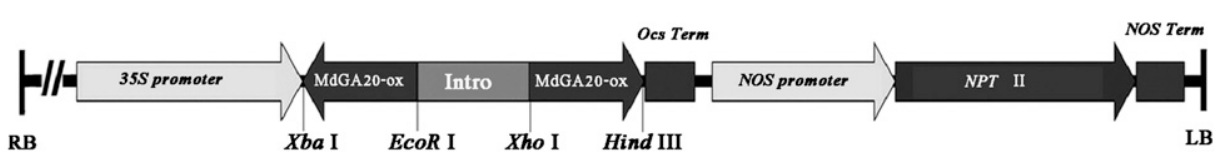

Fig. 1. Schematic drawing of the pRNAi-GA20ox construct. An inverted repeat was generated by cloning a sense fragment (MdGA20-ox $466 \mathrm{bp}$ ) followed by the antisense orientation in the pART27 vector backbone. The conserved sequence of 466 bp was used in developing the hpRNA binary vector for RNA interference; $\mathrm{RB}=$ right border, Ocs $=$ octopine synthase, $\mathrm{NOS}=$ nopaline synthase, $\mathrm{LB}=$ left border. kanamycin and $100 \mathrm{mg} \cdot \mathrm{L}^{-1}$ spectinomycin, and grown at $28{ }^{\circ} \mathrm{C}$ for $16 \mathrm{~h}$ on an orbital shaker at $165 \mathrm{rpm}$. The optical density at $600 \mathrm{~nm}$ $\left(\mathrm{OD}_{600)}\right.$ of bacterial solution was diluted to $\mathrm{OD}_{600}=0.1$ in $50 \mathrm{~mL}$ YEP and incubated at $25{ }^{\circ} \mathrm{C}$ with shaking for 5 to $6 \mathrm{~h}$ until $\mathrm{OD}_{600}=$ 0.5 . The first three apical expanding leaves were harvested from 4-week-

with $1 \mu \mathrm{L}$ RNase-free DNase I (TaKaRa Biotechnology, Dalian, China) at $37{ }^{\circ} \mathrm{C}$ for more than $4 \mathrm{~h}$.

ISOLATION OF MDGA20-OX GENE FRAGMENT AND CONSTRUCTION OF RNAI VECTOR. Forward and reverse primers (Table 1) were designed based on sequences of GA20-ox genes (GenBank accession numbers EB128368, EB132114, AB037114, EB126424, and EB127719). A fragment of the GA20-ox gene was amplified from the genomic DNA of 'Hanfu' and 'Pingyitiancha' by polymerase chain reaction (PCR). The $20-\mu \mathrm{L}$ PCR reactions included $50 \mathrm{ng}$ genomic DNA, $1 \times$ buffer, $1.8 \mathrm{mM} \mathrm{MgCl}_{2}, 0.2 \mu \mathrm{M}$ of each primer, $200 \mu \mathrm{M}$ of dNTPs, and $1 \mathrm{U}$ of Taq DNA polymerase (Invitrogen, Shanghai, China). The PCR program was as follows: $94{ }^{\circ} \mathrm{C}$ for $3 \mathrm{~min} ; 94$ at $30 \mathrm{~s}, 55$ at $1 \mathrm{~min}, 72^{\circ} \mathrm{C}$ $1 \mathrm{~min}, 35$ cycles; $72^{\circ} \mathrm{C}$ for $10 \mathrm{~min}$. To make a construct encoding a single self-complementary hairpin RNA (hpRNA) of the $M d G A 20-o x$ gene (Fig. 1), the sense and antisense fragments of the $M d G A 20$-ox gene were first inserted into the pKANNIBAL vector (Wesley et al., 2001). The recombinant pKANNIBAL vector and the plant expression vector pART27 were digested with NotI. The vector fragment including the MdGA20-ox gene sequence was ligated into the NotI-digested pART27.

Plant transformation. The RNAi construct was transferred into Agrobacterium tumefaciens strain EHA105 using the freeze-thaw method (Wang et al., 2011). The transformation method was used with leaf segments as explants. The transgenic system for 'Hanfu' has been previously established (Yang et al., 2010). The system was as follows: a single colony from the bacterial strain was inoculated into liquid yeast extract peptone (YEP) medium supplemented with $25 \mathrm{mg} \cdot \mathrm{L}^{-1}$ old proliferation shoots. Each leaf was transversely cut into 3 - to 4-mm segments. Leaf segments were shaken gently in the bacterial suspension for $10 \mathrm{~min}$ and blotted on a sterile filter paper. They were then cocultivated in bud regeneration medium [Murashige and Skoog (MS) supplemented with $2.0 \mathrm{mg} \cdot \mathrm{L}^{-1}$ thidiazuran, $0.2 \mathrm{mg} \cdot \mathrm{L}^{-1} \alpha$-naphthalene acetic acid] in darkness for $3 \mathrm{~d}$. Immediately after cocultivation, explants were washed three times with sterile distilled water to eliminate excess bacteria, blot-dried, and transferred into the bud regeneration medium supplemented with $250 \mathrm{mg} \cdot \mathrm{L}^{-1}$ cefotaxime and $25 \mathrm{mg} \cdot \mathrm{L}^{-1}$ kanamycin for selection culture. After selection culture, leaf explants were transferred to light conditions cultured for 4 weeks. When the regenerated buds were $\approx 1 \mathrm{~cm}$ long, they were excised and transferred into Type I shoot development medium [MS medium supplemented with $1.0 \mathrm{mg} \cdot \mathrm{L}^{-1}$ 6-benzylaminopurine $(6-\mathrm{BA}), 0.2 \mathrm{mg} \cdot \mathrm{L}^{-1}$ indole-3acetic acid (IAA)], $0.1 \mathrm{mg} \cdot \mathrm{L}^{-1} \mathrm{GA}_{3}, 250 \mathrm{mg} \cdot \mathrm{L}^{-1}$ cefotaxime, and $\left.25 \mathrm{mg} \cdot \mathrm{L}^{-1} \mathrm{kanamycin}\right)$. They were subcultured two times and then transferred into Type II shoot development medium (MS medium supplemented with $1.0 \mathrm{mg} \cdot \mathrm{L}^{-1} 6-\mathrm{BA}, 0.2 \mathrm{mg} \cdot \mathrm{L}^{-1}$ IAA, $1.0 \mathrm{mg} \cdot \mathrm{L}^{-1} \mathrm{GA}_{3}, 250 \mathrm{mg} \cdot \mathrm{L}^{-1}$ cefotaxime, and $25 \mathrm{mg} \cdot \mathrm{L}^{-1}$ kanamycin). Subculturing was carried out every 3 weeks to maintain selection pressure.

PCR ANALYSIS. PCR analysis was performed on isolated genomic DNA to detect the presence of transgene in the putative transformed plants using primers (PF4 and PR4) for the nptII gene (Table 1), which confers resistance to kanamycin, and a pair of primers (P5F and P5R) that amplifies the $35 \mathrm{~S}$ promoter region and the $M d G A 20$-ox gene was designed 
MdGA20-ox
MhGA20-ox
Consensus

TCTCCCCTGCTTTCCTTMAGCTCTCTGTTTTI.GGAGAG TCTCCCCTGCTTTCCTTIDAGCTCTCTGTTTTIAGGAGAG tctcccetgctttcctt agctctctgtttt ggagag

MdGA20-ox MhGA20-ox

Consensus

MdGA20-ox MhGA20-ox

Consensus

MdGA20-ox MhGA20-ox

Consensus

MdGA20-ox MhGA20-ox Consensus

MdGA20-ox MhGA20-ox Consensus

MdGA20-ox MhGA20-ox Consensus

MdGA20-ox MhGA20-ox Consensus

MdGA20-ox MhGA20-ox Consensus

MdGA20-ox MhGA20-ox Consensus

MdGA20-ox MhGA20-ox Consensus

MdGA20-ox MhGA20-ox Consensus

TGGCATTCCAAAAAAGTCATCCATGCAGCGGTGAGCGTCC TGGCATTCCAAAAAAGTCATCCATGCAGCGGTGAGCGTCC tggcattccaaaaagtcatccatgcagcggtgagcgtcc

GCGATGAGCGTATTGTCGACGCCGTGATTCACGATGAGGA GCGATGAGCGTATTGTCGACGCCGTGATTCACGATGAGGA gcgatgagcgtattgtcgacgccgtgattcacgatgagga

AAAATCCATGCTTCTGGCATGCCTCTCCTAOAGTTGCGA AAAATCCATGCTTCTGGCATGCCTCTCCTACAAGTTGCGA aaatccatgcttctggcatgcctctcctac agttgcga

GECTTICGCAGCGGCTTCTTTETCGCCCGAGAGAAAGCCT GGCTTICGCAGCGGCTTCTTTGTCGCCCGAGAGAAAGCCT ggctttcgcagcggcttctttgtcgcccgagagaaagcct

CCCAAGTCTATGAGTGG ACTCGGAGCTCGGGAGTATTTT CCCAAGTCTATGAGTGEA ACTCGGAGCTCGGGAGTATTTT cccaagtctatgagtgg actcggagctcgggagtattt

TECAAGGCTTTTCGTCATCGGGCCATATGAACTGACTCGG TECAAGGCTTTTCGTCATCGGGCCATATGAACTGACTCGG tgcaaggctttcgtcatcgggccatatgaactgactcgg

AATTTCAGTTTGGTACCTTAAAACTGAGGCATCAAAAACC AATTTCAGTTTGGTACCTTAAAACTGAGGCATCAAAAACC atttcagtttggtaccttaaaactgaggcatcaaaaacc AATGGTTTCTGGTCATCCTCTTTGTGCTECTGGGTTTTCT AATGGTTTCTGGTCATCCTCTTTGTGCTECTGGGTTTTCT aatggtttctggtcatcctctttgtgctgctgggttttct

GCGTTTGTGGGGAGGGAGGTTGTGCCATGGTTTGCATGCT GCGTTTGTGGGGAGGGAGGTTGTGCCATGGTTTGCATGCT gcgtttgtggggagggaggttgtgccatggtttgcatgct

\section{GCTGGGTTTGATCATGCACTCAACAGCCATTTTTGCATGA} GCTGGGTTTGATCATGCACTCAACAGCCATTTTTGCATGA gctgggtttgatcatgcactcaacagccattttgcatga

\section{ACAGAAAATGTATGTGAGTTGGGGAAG} ACAGAAAATGTATGTGAGTTGGGGAAG acagaaatgtatgtgagttggggaag

Fig. 2. Sequence alignment of the MdGA20-ox gene isolated from 'Hanfu' apple and the MhGA20-ox gene isolated from Malus hupehensis 'Pingyitiancha'.

(Table 1). The 20- $\mu \mathrm{L}$ PCR reactions included $50 \mathrm{ng}$ genomic DNA, $1 \times$ buffer, $1.8 \mathrm{~mm} \mathrm{MgCl}_{2}, 0.2 \mu \mathrm{M}$ of each primer, $200 \mu \mathrm{M}$ of dNTPs, and $1 \mathrm{U}$ of Taq DNA polymerase (Invitrogen). The PCR program was as follows: $94{ }^{\circ} \mathrm{C} 3 \mathrm{~min}$; 94 at $30 \mathrm{~s}, 55$ at $1 \mathrm{~min}, 72{ }^{\circ} \mathrm{C} 1 \mathrm{~min}, 35$ cycles; $72{ }^{\circ} \mathrm{C} 10 \mathrm{~min}$.
SEMIQUANTITATIVE AND QUANTITATIVE REVERSE TRANSCRIPTION-PCR ANALYSIS. Complementary DNA (cDNA) was synthesized from $3 \mu \mathrm{g}$ of total RNA using Superscript II reverse transcriptase (Invitrogen), following the manufacturer's instructions with oligo-(dT)-18 primer (TaKaRa Biotechnology). The Actin gene was selected as a positive control (Gasic et al., 2004).

For semiquantitative PCR analysis, the $50-\mu \mathrm{L}$ PCR reactions included $2 \mu \mathrm{L}$ cDNA (all cDNAs were quantified to the same concentration), $1 \times$ buffer, $1.8 \mathrm{mM} \mathrm{MgCl}_{2}$, $0.2 \mu \mathrm{M}$ of each primer, $200 \mu \mathrm{M}$ of dNTPs, and 1 U of Taq DNA polymerase. The PCR program was as follows: $94{ }^{\circ} \mathrm{C}$ for $2 \mathrm{~min}, 34$ cycles of 94,57 , and $72{ }^{\circ} \mathrm{C}$ for $1 \mathrm{~min}$ each cycle, and a final extension step of $72{ }^{\circ} \mathrm{C}$ for $5 \mathrm{~min}$. PCR products $(5 \mu \mathrm{L})$ were separated by $1.5 \%$ agarose electrophoresis.

Quantitative reverse transcription (RT)-PCR was conducted as described by Tan et al. (2013). Quantification of cDNA samples was performed in triplicate. Data were normalized against the value of the Actin gene. Relative fold changes in gene expression were calculated using the comparative $\mathrm{Ct}\left(2^{-\Delta \Delta \mathrm{Ct}}\right)$ method.

Phenotype analysis. Transgenic and nontransgenic lines were grown in a multiplication medium (MS medium supplemented with $1.0 \mathrm{mg} \cdot \mathrm{L}^{-1} 6-\mathrm{BA}, 0.2 \mathrm{mg} \cdot \mathrm{L}^{-1} \mathrm{IAA}$, and $\left.0.5 \mathrm{mg} \cdot \mathrm{L}^{-1} \mathrm{GA}_{3}\right)$. After 2 months, nine samples of each line were used to evaluate growth characteristics. Data on stem length, node number, and internode length were collected. All the transgenic lines and the nontransgenic control were transferred to the greenhouse at the same time. Stem height and internode length were measured after 20 weeks in

466 the greenhouse. Stem height was 467 measured from the bottom to the tip. Internode length was calculated as stem height divided by the number of leaves. Comparisons for multiple treatments were analyzed using Duncan's multiple range tests and the significance level was determined at 5\% using SPSS (version 17.0; IBM Corp., Armonk, NY).

Determination of GA contents. One gram fresh weight of leaves (control and transgene lines) at the same developmental stage were harvested and stored in liquid $\mathrm{N}_{2}$ and were ground 
into fine powder in a chilled mortar with chilled $80 \%(\mathrm{v} / \mathrm{v})$ methanol. Extraction, purification, and immunoassay of GAs were performed as described by $\mathrm{Wu}$ et al. (2008)using a $\mathrm{GA}_{1+3}$ enzyme-linked immunosorbent assay (ELISA) kit (Nanjing Agricultural University, Nanjing, China). Finally, the absorbance at $490 \mathrm{~nm}$ was recorded using an ELISA analyzer.

\section{Results}

Construction of an RNAi vector for the MdGA20-ox GENE. A 466-bp fragment of the GA20-ox gene was amplified from both 'Hanfu' and 'Pingyitiancha' lines, and the nucleotide sequence identity of the two apple species was $99.15 \%$ (Fig. 2). The fragment from 'Hanfu' was used as the sense and antisense fragment to create the RNAi hairpin construct for the MdGA20-ox gene (Fig. 1). The RNAi vector for the $M d G A 20$-ox gene was successfully constructed verified by enzyme digested and sequenced, then named pRNAi-GA20ox.
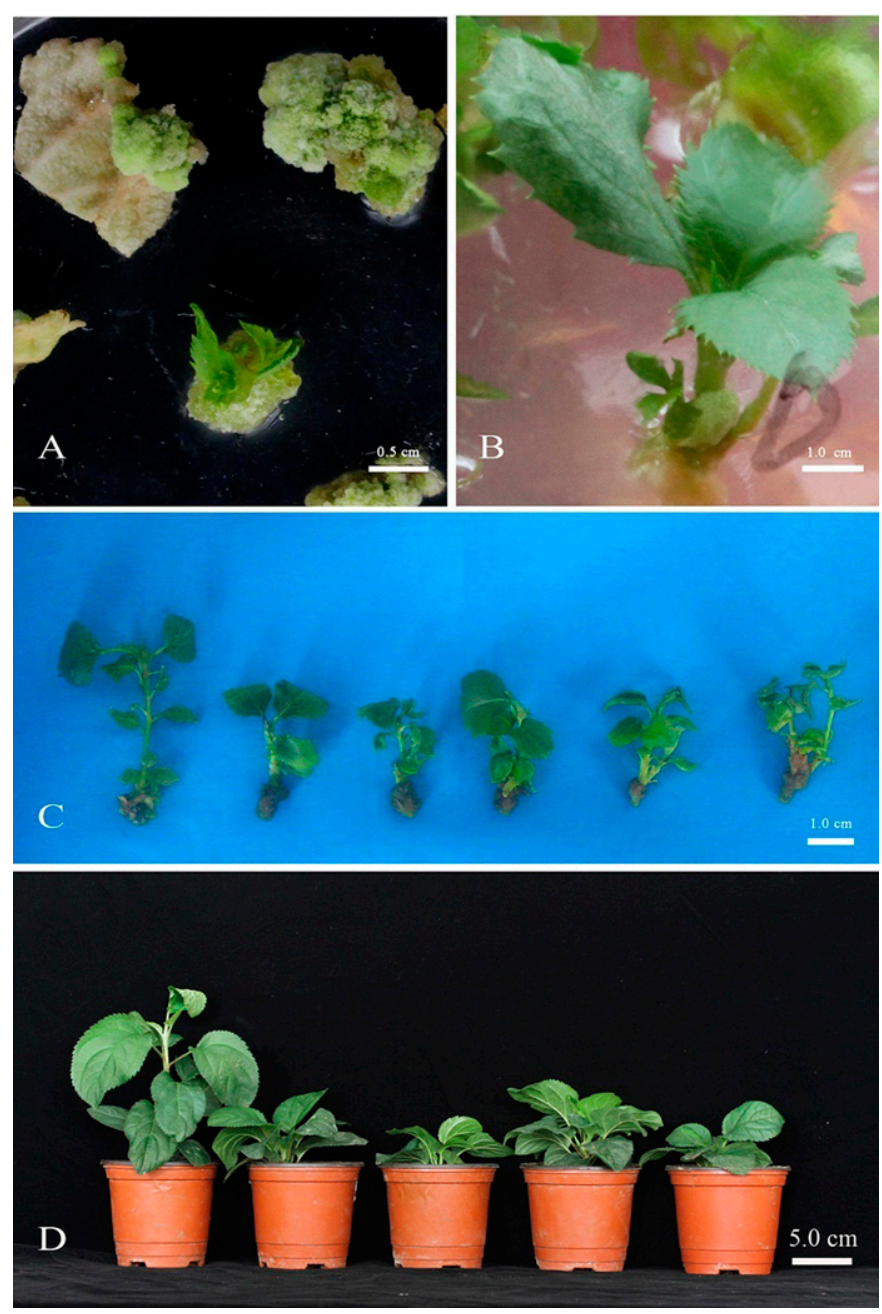

Fig. 3. Transformation of 'Hanfu' apple with interference RNA vector for the MdGA20-ox gene. (A) Kanamycin-resistant bud regenerated from leaf explants after 6 weeks of cultured; (B) kanamycin-resistant bud developed into a shoot after 2 months cultured in Type II medium; (C) phenotypes of nontransgenic control and the transgenic plants after 2 months cultured in Type II medium, from left to the right: nontransgenic control, transgenic lines (T-HF1,T-HF2, T-HF3, T-HF4, and T-HF5); (D) height of transgenic plants after 20 weeks in the greenhouse, from left to the right: nontransgenic control, transgenic lines T-HF1, T-HF3, T-HF4, and T-HF5.

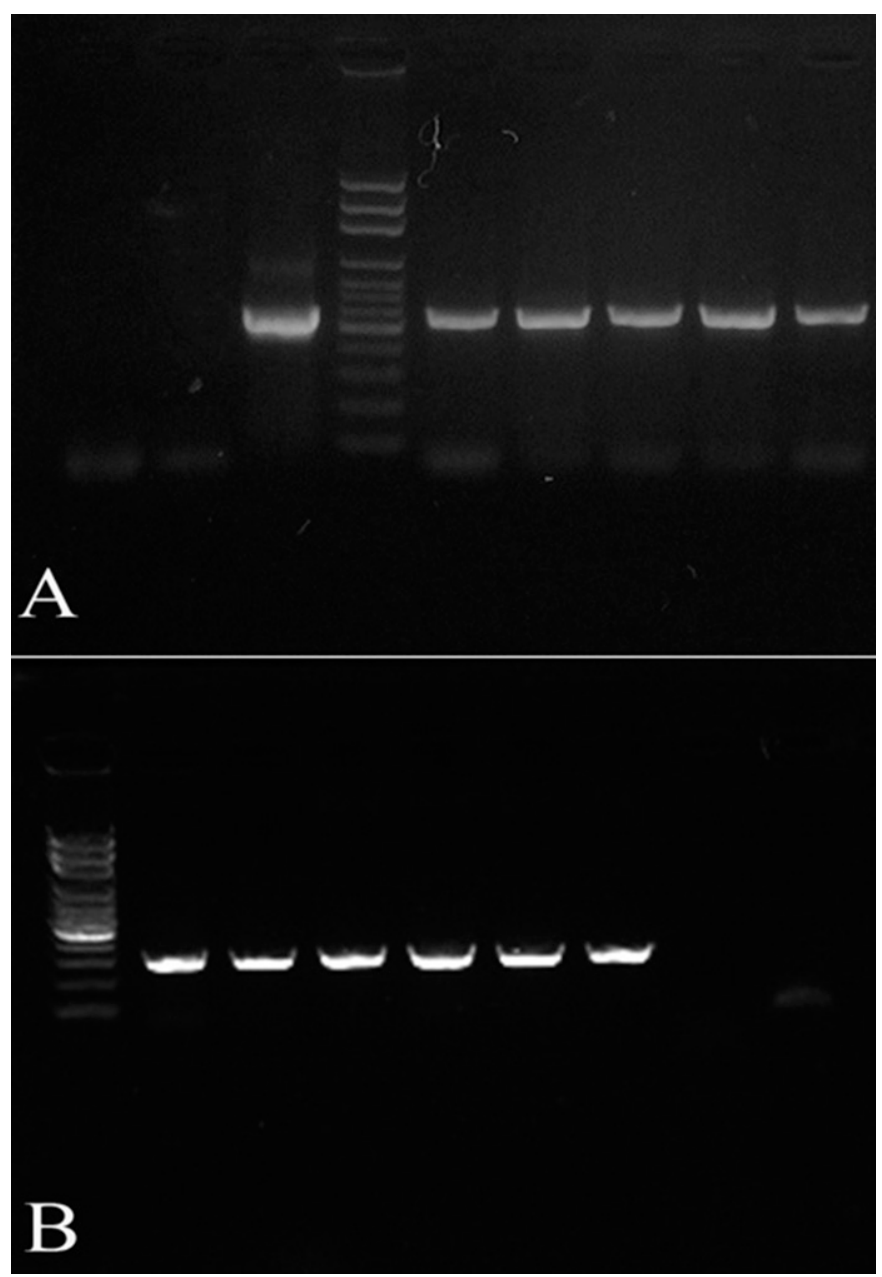

Fig. 4. PCR analysis for detection of transgenic lines. (A) PCR analysis for $n p t$ II, lanes from left to right: nontransgenic control, negative control (without DNA template), positive control of pRNAi-GA20ox, 100-bp molecular size marker, transgenic lines T-HF1, T-HF2, T-HF3, T-HF4, T-HF5 (M); (B) PCR analysis for the MdGA20-ox gene, lanes from left to right: 100-bp molecular size marker, transgenic lines T-HF1, T-HF2, T-HF3, T-HF4, T-HF5, positive control of pRNAi-GA20ox, nontransgenic control, and negative control (without DNA template).

Development OF KANAMYCIN-RESISTANT Plants. Twentyseven kanamycin-resistant buds (Fig. 3A) were regenerated from 9485 leaf explants, and the transformation rate was $0.28 \%$. After 2 months of culture in Type I medium, buds were less than $1 \mathrm{~cm}$ long with very small leaves. Then transferred into Type II medium, they had developed into green shoots 4 months later (Fig. 3B).

Molecular analysis of Transgenic plants. PCR results revealed that the 562-bp fragment for the $n p t \mathrm{II}$ gene (Fig. 4A) and the 400-bp fragment for the 35 S promoter and MdGA20-ox gene (Fig. 4B) were amplified from all five kanamycin-resistant lines. No amplification products were detected in the nontransgenic control plants. So, all the five kanamycin-resistant lines, T-HF1 to T-HF5, were transgenic lines.

Phenotypes of Transgenic Lines. For in vitro plants, leaves of transgenic lines were small and dark green, and all transgenic plants were significantly lower in height than the nontransgenic control plants grown in the same multiplication medium (Fig. 3C). The shortest transgenic line was T-HF2, with an average height 
of $2 \mathrm{~cm}, 43 \%$ lower than that of the nontransgenic control $(3.5 \mathrm{~cm})$. The highest transgenic line was T-HF1, with an average height of $2.9 \mathrm{~cm}, 20 \%$ lower than that of the nontransgenic control (Table 2). The node number of transgenic lines was significantly higher (1.3- to 1.5 -fold) than that of the nontransgenic control (Table 2). The transgenic plants were shorter with more nodes, and therefore the length of internodes in the transgenic lines was significantly shorter than that in the nontransgenic control (Table 2).

In vitro plants were transferred into a greenhouse in early May 2014. Nontransgenic control plants and transgenic lines were survived in the greenhouse, except for T-HF2 (died of fungal infections). Phenotypes were measured after plants grew in the greenhouse for 20 weeks. No significant differences were observed in the leaf color between transgenic plants and nontransgenic control, but the height of transgenic plants [T-HF1 $(5.00 \mathrm{~cm})$, T-HF3 $(4.20 \mathrm{~cm})$, T-HF4 $(6.35 \mathrm{~cm})$, T-HF5 $(3.43 \mathrm{~cm})]$ was significantly lower than that of the nontransgenic control $(16.5 \mathrm{~cm})$ (Fig. 3D). No transgenic lines were over $50 \mathrm{~cm} 1$ year after grew in greenhouse, while the transgenic lines were only $18 \%$ to $35 \%$ of the no transgenic lines.

EXPRESSION LEVELS OF THE MDGA20-OX GENE IN TRANSGENIC LINES. Semiquantitative RT-PCR was used to analyze the expression of $M d G A 20-o x$ gene in in vitro plants. As shown in Fig. 5, $M d G A 20-o x$ genes showed distinct patterns of transcript accumulation between transgenic plants and the nontransgenic control. The band amplified from the nontransgenic control was clear and strong, whereas the bands amplified from transgenic lines were weak. The expression of MdGA20-ox gene in plants that grew in the greenhouse was measured by quantitative RT-PCR. Because the plants of T-HF3 died of disease in the greenhouse, only T-HF1, T-HF4, and T-HF5 were used for quantitative RT-PCR. The results revealed that expression levels of the MdGA20-ox gene were $4.79 \%$ for T-HF $1,18.99 \%$ for T-HF4, and $14.76 \%$ for T-HF5, when relative quantification of the MdGA20-ox gene was set to $100 \%$ (Fig. 6).

EFFECT OF SUPPRESSING MDGA20-OX GENE EXPRESSION ON GA contents. GA content in leaves of in vitro plants was measured by ELISA. As shown in Fig. 7, GA content in all transgenic lines was reduced compared with that in the nontransgenic control plants, and the correlation between the GA content and the length of internodes was significantly positive $(r=0.93)$.

\section{Discussion}

GA is a phytohormone involved in many aspects of plant development. The most obvious function of GA is the promotion of vegetative growth, particularly of plant height (Hannon, 2002; Hedden and Phillips, 2000). GA biosynthetic pathway has been well characterized and can be divided into three major stages according to the localization (Lee and Zeevaart, 2007), and the enzymes involved. GA20-ox catalyzes the final steps in the biosynthesis of biologically active GA (Zhao et al., 2010). GA20-ox gene encoded by a gene family whose members show differential expression patterns (Hedden and Phillips, 2000), whereas in Arabidopsis thaliana, GA20-ox were encoded by five genes. GA20-ox1, GA20-ox2, and $G A 20-o x 3$ are important to growth and fertility, which are active in flowers and seeds, whereas GA20-ox4 and GA20-ox5 have very minor roles. Concentrations of $\mathrm{GA}_{4}$ in GA-deficient mutants (ga20-ox1, ga20-ox2, ga20-ox3) were $\approx 50 \%$ of
Table 2. Phenotypes change in average height, length per nodes, and numbers of nodes of control and transgenic plants of 'Hanfu' apple cultured in vitro. ${ }^{z}$

\begin{tabular}{|c|c|c|c|}
\hline \multirow[b]{2}{*}{ Line } & Avg ht & Length per node & \multirow{2}{*}{$\frac{\text { Nodes }}{[\text { mean } \pm \text { SD }(\text { no. })]}$} \\
\hline & \multicolumn{2}{|c|}{$[$ mean \pm SD $(\mathrm{cm})]$} & \\
\hline Control & $3.55 \pm 0.44 \mathrm{a}^{\mathrm{y}}$ & $1.08 \pm 0.17 \mathrm{a}$ & $3.38 \pm 0.92 \mathrm{~d}$ \\
\hline T-HF1 & $2.86 \pm 0.24 \mathrm{~b}$ & $0.67 \pm 0.10 \mathrm{~b}$ & $4.33 \pm 1.22 \mathrm{c}$ \\
\hline T-HF2 & $2.36 \pm 0.36 \mathrm{~d}$ & $0.45 \pm 0.10 \mathrm{~d}$ & $4.33 \pm 1.50 \mathrm{c}$ \\
\hline T-HF3 & $2.31 \pm 0.37 \mathrm{~d}$ & $0.44 \pm 0.09 \mathrm{~d}$ & $4.50 \pm 1.18 \mathrm{~b}$ \\
\hline T-HF4 & $2.61 \pm 0.32 \mathrm{c}$ & $0.57 \pm 0.06 \mathrm{c}$ & $4.57 \pm 0.98 b$ \\
\hline T-HF5 & $2.81 \pm 0.47 \mathrm{~b}$ & $0.58 \pm 0.14 \mathrm{c}$ & $5.00 \pm 1.51 \mathrm{a}$ \\
\hline
\end{tabular}

${ }^{\mathrm{z}}$ All samples were harvested in vitro cultured for 4 mo. The average height was measured from the bottom to the tip. The internodes length was calculated by dividing the stem height with leaf numbers. The numbers of node was statistical from the bottom to the tip.

${ }^{y}$ Different letters within the same column indicate significant difference at $P<0.05$ by Duncan's test.

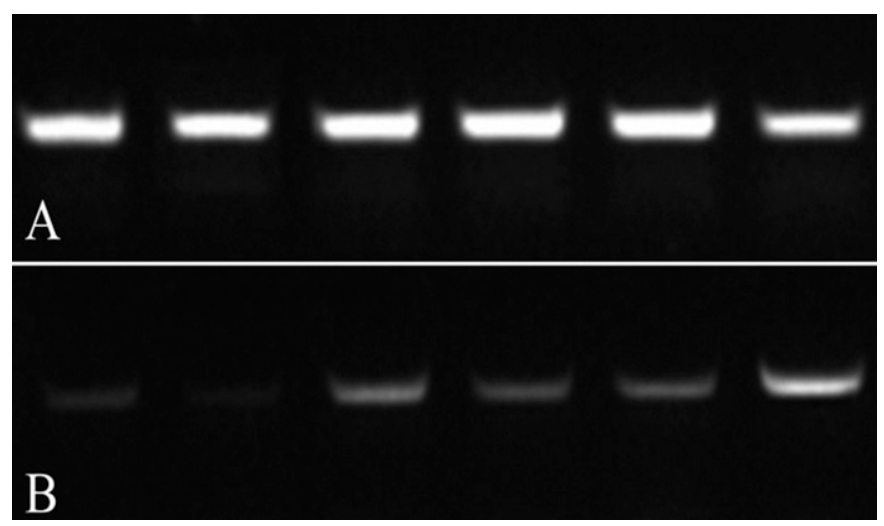

Fig. 5. Expression levels of the MdGA20-ox gene in 'Hanfu' apple transgenic lines and the nontransgenic control detected by semiquantitative reverse transcription-PCR. (A) Expression levels of Actin gene, lanes from left to right: transgenic lines T-HF1, T-HF2, T-HF3, T-HF4, T-HF5, nontransgenic control; (B) Expression levels of the MdGA20-ox gene, lanes from left to right: transgenic lines T-HF1, T-HF2, T-HF3, T-HF4, T-HF5, and nontransgenic control.

the wild types (Plackett et al., 2012). Decrease of GA20-ox1 or GA20-ox 2 expression by RNAi resulted in shorter stems, decreased length of internodes, and small dark green leaves (Xiao et al., 2006). Leaf thickness was smaller in sense and larger in antisense CcGA20ox1 plants (Fagoaga et al., 2007). The height of transgenic lines of OsGA20ox2 RNAi (dwarf lines and semidwarf lines) was $\approx 75 \%$ to $84 \%$ and $54 \%$ to $74 \%$ of that of the control plants, and the semidwarf lines could be restored to normal plant height by applying exogenous $\mathrm{GA}_{3}$ (Qiao and Zhao., 2011). A pair of degenerate primer was designed based on the 466-bp fragment of MdGA20-ox genes (common base sequences of $M d G A 20-o x 1$, ox2, and ox3) in this study for constructing the RNAi vector to suppress $M d G A 20-o x$ gene expression, and we obtained dwarf lines of 'Hanfu' apple with short internodes. Bulley et al. (2005) have suppressed the expression of MpGA20oxl gene by antisense RNA, resulting in reduced the stem height, greatly reduced contents of $\mathrm{GA}_{1}$, and decreased number of internodes. There were some differences with our studies. First, transgenic line heights of our study were more shorter because RNAi was more efficient than antisense RNA in gene 


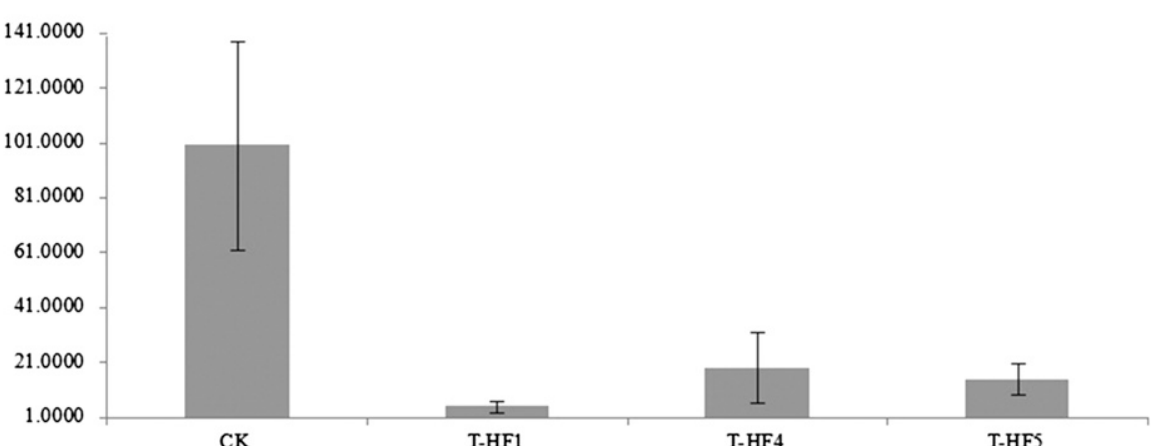

Fig. 6. Expression levels of the MdGA20-ox gene in 'Hanfu' apple transgenic lines and the nontransgenic control detected by quantitative reverse transcription-PCR. From left to right: nontransgenic control (CK), transgenic lines T-HF1, T-HF4, and T-HF5.

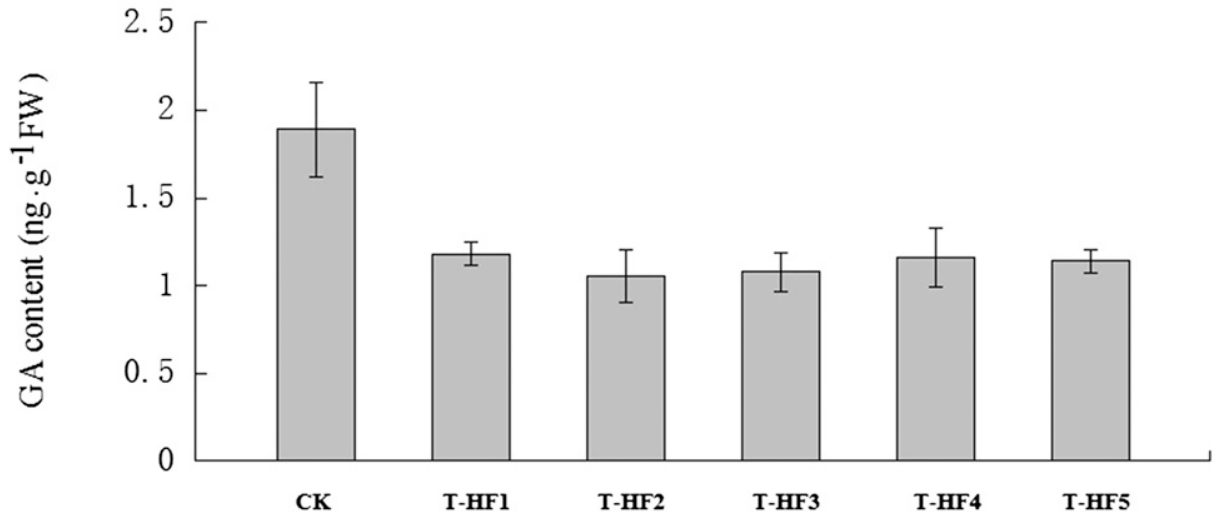

Fig. 7. Endogenous active gibberellic acid content $\left(\mathrm{GA}_{1+3}\right)$ in the leaves of 'Hanfu' apple nontransgenic control and the transgenic lines. From left to right: nontransgenic control (CK), transgenic lines T-HF1, T-HF2, T-HF3, T-HF4, and T-HF5.

silencing. GA20-ox of apple was encoding by three genes. There were several differences in base sequences of the three genes (MdGA20-ox1, ox2, and ox3, which are usually not active in leaves), and even more, the $466 \mathrm{bp}$ for silencing was the base on the common base sequences of the three genes (a pair of primer was designed only for MdGA20-oxl), so we believed that silencing of MdGA20-ox was the cause of decrease of GA active (could unaffected other genes). Second, buds regenerated from Type I medium were less than $1 \mathrm{~cm}$ long cultured for 2 months, we realized that GA deficient was the main cause. Therefore, we transferred them into Type II medium cultured for 4 months. GA contents and growth parameter were measured at this time. So GA contents were higher and the number of internodes were increased in our study. And even more, the real contents of $\mathrm{GA}_{3}$ may be more lower because we promoted $\mathrm{GA}_{3}$ in the Type II medium, but the nontransgenic and transgenic lines were grew in the same medium, so the relative relationship between them was true. Our results demonstrated that (as also shown by Bulley et al., 2005 ) the GA20-ox gene plays an important role in vegetative growth of apple and it is possible to develop compact scions by suppressing MdGA20-ox gene expression. GA20-ox gene is tissue specific, which mainly expresses in immature seeds (Kusaba et al., 2001), leaves and flowers (Ashikari et al., 2002), and GA deficiency also impact on fertility (Plackett et al., 2012). So, the transgenic lines obtained in this study maybe have low fertility.

RNAi is an efficient and stable transgenic method for gene silencing. The silencing effect can spread to adjacent cells or over the whole organism. It can spread from cell to cell over short distances, locally extensive or systemically via phloem (Kalantidis et al., 2008). The most promising genetic engineering technology for fruit and nut tree crops maybe produce transgenic rootstocks (Haroldsen et al., 2012a), which could be grafted with nontransgenic scions. In this case, it potentially mollifies consumer concerns with eating transgenic fruits. This approach would also address the need to affect many cultivars with one rootstock. An accumulation of small interference RNAs derived from hairpin constructs was observed in kernels of a wild-type scion grafted on a transgenic rootstock in annual crops (Haroldsen et al., 2012b). The spread of RNA gene-silencing signals through graft junctions has been evaluated in fruit trees. For example, in a preliminary experiment, virus resistance was seen in sour cherry (Prunus cerasus) trees grafted onto a virus-resistant rootstock that was resistant through production of sRNAs (Song et al., 2013). A graft transmission of silencing signals in in vitro shoots was demonstrated in transgenic apple plants, overexpressing an hpRNA construct of gusA reporter gene. However, this could not be detected again once the scion grew in field (Flachowsky et al., 2012). In that case, lignification is generally detrimental for systemic silencing. On the other hand, it would open the possibility to down-regulate specific genes in rootstocks without influencing scions.

Our preliminary study of graft transmission in vitro (we observed that the shoots of nontransgenic apple plants grafted in vitro onto T-HF3 were shorter than those grafted onto nontransgenic 'Hanfu') has indicated that the scions are shorter suggesting that small RNAs may cross the graft junction and affect the production of GAs in the scion. Further work is being pursued on this.

\section{Conclusions}

To investigate the role of GA in the growth and development of apple, we applied RNAi technology to suppress MdGA20-ox gene expression. Our results showed that suppression of MdGA20-ox gene expression resulted in lower plant height, shorter internode length, and higher number of nodes, small and dark green leaves compared with the nontransgenic control in vitro. A significant difference in plant height was observed in 
the greenhouse too. The expression of MdGA20-ox in transgenic plants was significantly suppressed by a small hpRNA construct, and the active GA contents in transgenic lines were lower than that in the nontransgenic control. Overall, dwarf apple plants can be developed with the application of RNAi technology.

\section{Literature Cited}

Ashikari, M., A. Sasaki, M. Ueguchi, H. Itoh, A. Nishimura, S. Datta, K. Ishiyama, T. Saito, M. Kobayashi, G.S. Khush, H. Kitano, and M. Matsuoka. 2002. Loss-of-function of a rice gibberellin biosynthetic gene, GA20 oxidase (GA20ox-2), led to the rice 'green revolution'. Breed. Sci. 52:143-150.

Atkinson, C. and M. Else. 2001. Understanding how rootstocks dwarf fruit trees. Compact Fruit Tree 34:46-49.

Bulley, S.M., F.M. Wilson, P. Hedden, A.L. Phillips, S.J. Croker, and D.J. James. 2005. Modification of gibberellin biosynthesis in the grafted apple scion allows control of tree height independent of the rootstock. Plant Biotechnol. J. 3:215-223.

Chang, L., Z. Zhang, H. Yang, H. Li, and H. Dai. 2007. Detection of strawberry RNA and DNA viruses by RT-PCR using total nucleic acid as a template. J. Phytopathol. 155:431-436.

Fagoaga, C., F.R. Tadeo, D.J. Iglesias, L. Huerta, I. Lliso, A.M. Vidal, and L. Pena. 2007. Engineering of gibberellin levels in citrus by sense and antisense overexpression of a GA20-oxidase gene modifies plant architecture. J. Expt. Bot. 58:1407-1420.

Flachowsky, H., C. Trankner, I. Szankowski, S. Waidmann, M.V. Hanke, D. Treutter, and T.C. Fischer. 2012. RNA-mediated gene silencing signals are not graft transmissible from the rootstock to the scion in greenhouse-grown apple plants Malus sp. Int. J. Mol. Sci. 13:9992-10009.

Gasic, K., A. Hernandez, and S.S. Korban. 2004. RNA extraction from different apple tissues rich in polyphenols and polysaccharides for cDNA library construction. Plant Mol. Biol. Rep. 22:437-438.

Hannon, G.J. 2002. RNA interference. Nature 418:244-251.

Haroldsen, V., G. Paulino, C. Chi-Ham, and A. Bennett. 2012a. Research and adoption of biotechnology strategies could improve California fruit and nut crops. Calif. Agr. 66(2):62-69.

Haroldsen, V., M.W. Szczerba, H. Aktas, J. Lopez-Baltazar, M.J. Odias, C.L. Chi-Ham, J.M. Labavitch, A.B. Bennett, and A.L. Powell. 2012b. Mobility of transgenic nucleic acids and proteins within grafted rootstocks for agricultural improvement. Front. Plant Sci. 3:39.

Hedden, P. and A.L. Phillips. 2000. Gibberellin metabolism: New insights revealed by the genes. Trends Plant Sci. 5:523-530.

Kalantidis, K., H.T. Schumacher, T. Alexiadis, and J.M. Helm. 2008. RNA silencing movement in plants. Mol. Biol. Cell 100:13-26.

Kusaba, S., C. Honda, and Y. Kano-Murakami. 2001. Isolation and expression analysis of gibberellin 20-oxidase homologous gene in apple. J. Expt. Bot. 52:375-376.

Lee, D.J. and J.A. Zeevaart. 2007. Regulation of gibberellin 20-oxidase1 expression in spinach by photoperiod. Planta 226:35-44.

Olszewski, N., T.P. Sun, and F. Gubler. 2002. Gibberellin signaling, biosynthesis, catabolism, and response pathways. Plant Cell 14:S61-S80.
Plackett, A.R., S.J. Powers, N. Fernandez-Garcia, T. Urbanova, Y. Takebayashi, M. Seo, and P. Hedden. 2012. Analysis of the developmental roles of the Arabidopsis gibberellin 20-oxidases demonstrates that GA20ox1,-2, and-3 are the dominant paralogs. Plant Cell 24:941-960.

Qiao, F. and K.J. Zhao. 2011. The influence of RNAi targeting of OsGA20ox2 gene on plant height in rice. Plant Mol. Biol. Rep. 29:952-960.

Song, G.Q., K.C. Sink, A.E. Walworth, M.A. Cook, R.F. Allison, and G.A. Lang. 2013. Engineering cherry rootstocks with resistance to Prunus necrotic ring spot virus through RNAi-mediated silencing. Plant Biotechnol. J. 11:702-708.

Tai, T.H. and S.D. Tanksley. 1990. A rapid and inexpensive method for isolation of total DNA from dehydrated plant tissue. Plant Mol. Biol. Rep. 8:297-303.

Talwara, S., B.W.W. Grout, and A. Toldam. 2013. Modification of leaf morphology and anatomy as a consequence of columnar architecture in domestic apple Malus domestica Borkh trees. Sci. Hort. 164:310315.

Tan, D.M., T.Z. Li, and A.D. Wang. 2013. Apple 1-Aminocyclopropane1 -carboxylic acid synthase genes, MdACS1 and MdACS3a, are expressed in different systems of ethylene biosynthesis. Plant Mol. Biol. Rep. 31:204-209.

Wang, S.S., Z.Z. Liu, C. Sun, Q.H. Shi, Y.X. Yao, C.X. You, and Y.J. Hao. 2012a. Functional characterization of the apple MhGAI1 gene through ectopic expression and grafting experiments in tomatoes. J. Plant Physiol. 169:303-310.

Wang, S.S., C. Sun, Z.Z. Liu, Q.H. Shi, Y.X. Yao, C.X. You, and Y.J. Hao. 2012b. Ectopic expression of the apple mhgai2 gene brings about GA-insensitive phenotypes in tomatoes. Acta Physiol. Plant. 34:2369-2377.

Wang, X.Q., X. Shen, Y.M. He, T.N. Ren, W.T. Wu, and T. Xi. 2011. An Optimized freeze-thaw method for transformation of Agrobacterium tumefaciens EHA105 and LBA4404. Pharm. Biotechnol. 18:382-386.

Wesley, S.V., C.A. Helliwell, N.A. Smith, M. Wang, D.T. Rouse, and Q. Liu. 2001. Construct design for efficient, effective and highthroughput gene silencing in plants. Plant J. 27:581-590.

Wiesman, Z. and S. Lavee. 1994. Vegetative growth retardation, improved rooting and viability of olive cuttings in response to application of growth retardants. Plant Growth Regulat. 14:83-90.

$\mathrm{Wu}$, T., J.S. Cao, and Y. Zhang. 2008. Comparison of antioxidant activities and endogenous hormone levels between bush and vine-type tropical pumpkin (Cucurbita moschata Duchesne). Sci. Hort. 116:27-33.

Xiao, J., H. Li, J. Zhang, R. Chen, Y. Zhang, B. Ou, T. Wang, and Z. Ye. 2006. Dissection of GA20-oxidase members affecting tomato morphology by RNAi-mediated silencing. Plant Growth Regulat. 50:179-189.

Yamaguchi, S. 2008. Gibberellin metabolism and its regulation. Annu. Rev. Plant Biol. 59:225-251.

Yang, Y., Z.H. Zhang, Y.X. Liu, P. He, Y. Zhou, H.Y. Dai, and G.L. Zhao. 2010. Establishment of Agrobacterium tumefaciens-mediated transformation system for Hanfu apple. J. Fruit Sci. 27:174-178.

Zhao, H., J. Dong, and T. Wang. 2010. Function and expression analysis of gibberellin oxidases in apple. Plant Mol. Biol. Rep. 282:231-238. 